\title{
AVALIAÇÃO DE INDICADORES INFLAMATÓRIOS NO DIAGNÓSTICO DA MAMITE OVINA
}

\author{
G.R. Nunes, M.G. Blagitz, C.B. Freitas, F.N. Souza, M. Ricciardi, C.R. Stricagnolo, \\ B.G.S. Sanches, M.R. Azedo, M.C.A. Sucupira, A.M.M.P. Della Libera
}

Universidade de São Paulo, Faculdade de Medicina Veterinária e Zootecnia, Departamento de Clínica Médica, Av. Prof. Dr. Orlando Marques de Paiva, 87, CEP 05508-270, São Paulo, SP, Brasil. E-mail: giovannarocha@hotmail.com

\section{RESUMO}

\begin{abstract}
O objetivo do presente trabalho foi avaliar diferentes indicadores inflamatórios no diagnóstico da mamite em ovinos da raça Santa Inês. Após a realização do examefísico das mamas e a prova de fundo escuro, foram coletadas e analisadas 390 amostras de leite, sendo as metades mamárias divididas de acordo com o exame bacteriológico e a prova de fundo escuro, resultando em 290 amostras negativas em ambos os exames, 90 amostras negativas à prova de fundo escuro e positivas na cultura bacteriológica, 5 amostras positivas à prova de fundo escuro e negativas ao exame bacteriológico e 3 amostras positivas em ambos os testes. Nestas amostras foram realizadas a contagem automática de células somáticas (CCS), o California Mastitis Test (CMT), a determinação da concentração hidrogeniônica $(\mathrm{pH})$ e dos teores de cloreto e lactose, e ainda a avaliação do índice de cloreto-lactose. Os maiores valores preditivos foram observados para a CCS, CMT e teor de cloreto; o $\mathrm{pH}$, o teor de lactose e o índice cloreto-lactose apresentaram-se como marcadores inflamatórios menos sensíveis, onde se considerou o resultado da cultura bacteriológica como padrão ouro. O exame físico não se mostrou como método diagnóstico seguro quando utilizado isoladamente, exaltando a importância da associação de outros meios diagnósticos indiretos.
\end{abstract}

PALAVRAS-CHAVE: Mamite, ovinos, indicadores inflamatórios, contagem de células somáticas.

\section{ABSTRACT}

EVALUATION OF THE INDICATORS OF INFLAMMATION IN THE DIAGNOSIS OF OVINE MASTITIS. The aim of this trial was to evaluate distinct indictors of inflammation in the diagnosis of mastitis in Santa Ines ewes. The physical examination and the dark bottom cup test were performed. Afterwards, the bacteriologic samples of 390 milk samples were analyzed. The samples were divided according to the bacteriological examination and the dark cup bottom test, resulting in 290 samples negative in both tests, 90 samples positive in the bacteriological examination and negative in the dark cup bottom test, 5 samples positive in the dark cup bottom test and negative in bacteriological culture, and 3 samples positive in both tests. The automatic somatic cell count (SSC), the California mastitis test (CMT), the $\mathrm{pH}$, the chloride and lactose content, and the chloride-lactose number were established. Then, their predictive value as a indicator of inflammation was calculated assuming the bacteriologic examination as the gold standard test. The CCS, CMT and chloride content proved to be the best predictors, while the $\mathrm{pH}$, the lactose content and chloride-lactose number were the least sensitive tests. The physical examination was revealed to be a nonsensitive diagnostic procedure when used as the only procedure to detect the disease, showing that other diagnostics tests are required.

KEY WORDS: Mastitis, sheep, indicators of inflammation, somatic cell count.

\section{INTRODUÇÃO}

A mamite é um processo inflamatório mamário usualmente causado por bactérias. Os estudos relacionados a esta doença se iniciaram há pouco mais de um século, tendo uma vasta literatura acumulada sobre o assunto, porém grande parte destes estudos concentra-se na espécie bovina. Deve-se ressaltarque as informações sobre as doenças da glândula de ovinos são ainda mais restritas para os ovinos não especializados para a produção leiteira (BLAGITZ,2007).

Esta doença é a principal razão para o descarte de ovelhas, tendo a mamite inaparente, considerada como subclínica, o maior efeito na redução da produ- 
ção e na qualidade do leite, levando a prejuízos maiores que aqueles observados em bovinos leiteiros (Leitner et al., 2001; GonZAlo et al., 2002). A mamite também está associada com a performance dos cordeiros, descarte de ovelhas, mortes, custos com tratamentos e gastos adicionais com mão-de-obra (GREEN, 1984; FTHENAKIS;JONES, 1990; LARSGRAD;VAABENOE,1993).

A detecção definitiva da mamite é baseada no isolamento de patógenos através da coleta asséptica das amostras de leite (McDougAll et al., 2001). No entanto, o exame bacteriológico apresenta limitações devido à exigência de exames laboratoriais, tempo requerido para a cultura e custos. Adicionalmente a isto, os testes bacteriológicos não são confiáveis (McDougall et al., 2001; PYÖrallä, 2003). De fato, a ocorrência da mamite pode não ser acompanhada pelo isolamento do agente etiológico por várias razões: (1) o microrganismo pode não ser eliminado intermitentemente ou ser eliminado em baixas concentrações; (2) patógenos que não são detectados pelos exames bacteriológicos usuais; (3) algumas enzimas e proteínas lácteas (lisozima e lactoferrina) podem dificultar a detecção do patógeno e (4) a infecção ser suportada por endotoxinas bacterianas e compostos bio-ativos liberados pelas células inflamatórias que podem prejudicar a sobrevivência bacteriana (McDougall et al., 2001; RuegG; Reinemann, 2002; PYÖRALLÄ, 2003), sendo reportado que o isolamento bacteriano pode não ser identificado em mais de $50 \%$ das amostras (MARKovec; RUEGG, 2002).

A mamite ocasiona mudanças na composição láctea, sendo sua extensão dependente da resposta inflamatória (Auldist et al., 1995). A amplitude da mudança está subordinada à patogenicidade doagente etiológico envolvido e à área tecidual afetada, em especial a epitelial (PYörAllä, 2003). As principais alterações na mama incluem a passagem de íons, proteínas e enzimas do sangue para o leite devido ao aumento da permeabilidade, invasão de fagócitos e redução da capacidade de síntese láctea da glândula (McDougall et al., 2001). Alguns componentes são mais marcantes que outros, podendo ser utilizados como ferramenta para a detecção do processo inflamatório (PYöRALlä, 2003).

Assim, testes indiretos como a contagem de células somáticas (CCS), o California Mastitis Test (CMT), a concentração hidrogeniônica $(\mathrm{pH})$, o conteúdo de cloreto e lactose, e o índice de cloreto-lactosetornamse necessários para o diagnóstico da mamite ou para a seleção de animais para subseqüente análise bacteriológica, para tratamento ou descarte (MulKalwar et al., 2001; McDougall etal., 2001;RuegG; ReinemanN, 2002; Lafi, 2006). Todas estas decisões necessitam que valores de cortes destes testes sejam estabelecidos para discriminar os animais sadios dos infectados (RuEgG; REINEMANN, 2002). Custos e o tem- po requerido para a cultura bacteriológica devem ser cuidadosamente avaliados, especialmente em rebanhos não destinados à produção de leite onde o pagamento pela sua qualidade não é contabilizado. A mamite pode ser ainda diagnosticada pelo exame clínico da mama através de alterações na inspeção e na palpação, e pela prova de fundo escuro onde se busca avaliar alterações macroscópicas da secreção láctea (GRUNERT, 1993).

A precisão dos testes diagnósticos pode ser mensurada pela sensibilidade(SE), queé a proporção de animais doentes que são corretamente classificados como doentes, e pela especificidade (ES), que é denominada como a porcentagem de animais sadios que são devidamente enquadrados como sadios, sendo estes parâmetros inversamente relacionados. Os valores preditivos positivos (VPP) e negativos (VPN) são definidos como probabilidades que um animal sadio ou doente apresenta de ser classificado como tal, segundo o teste realizado. A razão de probabilidades (RP) é a probabilidade de um resultado positivo para um animal realmente doente comparado à probabilidade do mesmo resultado ocorrer em um animal sem a doença (McDougALl et al., 2001).

Neste trabalho objetivou-se, por meio das alterações do leite e na glândula mamária, avaliar o desempenho de distintos testes como CCS, CMT, concentração hidrogeniônica, conteúdo de cloretos e lactose, e índice de cloreto-lactose, além do exame clínico da mama na predição da presença bacteriana em amostras lácteas provenientes de metades mamárias sadias, e com mamite clínica e subclínica, com o intuito de se estabelecer meios diagnósticos auxiliares na identificação da mamite infecciosa de ovinos da raça Santa Inês.

\section{MATERIAIS E MÉTODOS}

\section{Animais e análises}

No presente estudo foram analisadas 390 amostras de leite de ovelhas Santa Inês provenientes do Estado de São Paulo, sendo as metades mamárias divididas de acordo com os resultados da cultura bacteriológica e da prova de fundo escuro (GRUNERT, 1993), conforme apresentado na Tabela 1. A cultura bacteriológica foi considerada como "padrão ouro" para a análise dos testes diagnósticos como proposto por CoNTRERAs et al. (2007). Inicialmente foi realizado o exame físico da glândula (BAUMGARTNER, 2005), que foi dividido em escores (0 para mamas com úberes e tetos normais na inspeção e palpação, 1 para mamas com úberes e/ou tetos alterados à inspeção e normais à palpação, 2 para mamas com úberes e/ou tetos normais à inspeção e alterados à palpação, e 3 com 
úberes e/ou tetos alterados à inspeção e a palpação). As amostras de leite, após devida assepsia, foram destinadas para a realização do exame bacteriológico, contagem automática de células somáticas (CCS), CMT (McDougall et al., 2001), concentração hidrogeniônica e teores de cloreto e lactose.

Tabela 1 - Formação dos grupos experimentais.

\begin{tabular}{lcc}
\hline $\begin{array}{l}\text { Cultura bacteriológica/ } \\
\text { Prova de fundo escuro }\end{array}$ & Negativa & Positiva \\
\hline Negativa & G1 & G3 \\
Positiva & G2 & G4 \\
\hline
\end{tabular}

No exame bacteriológico as amostras de leite coletadas foram semeadas em placa de Petri contendo ágar-sangue de carneiro $(5 \%)$ e incubadas a $37^{\circ} \mathrm{C}$ por 24 e 48 horas, para posterior identificação dos microrganismos através de provas bioquímicas descritas por LENNETTE et al. (1985), seguida da classificação conforme critérios estabelecidos por KRIEG; Holt (1994).

A determinação do conteúdo de cloreto (925 Chloride Analyzer, Corning ${ }^{\circledR}$, Homburg, Alemanha) e a concentração hidrogeniônica ( $\mathrm{pH}$-metro modelo B474 da Micronal ${ }^{\circledR}$, São Paulo, Brasil) foram determinadas em aparelhos destinados para tal finalidade. As amostras destinadas a CCS e ao teor de lactose foram encaminhadas e analisadas no Laboratório de Referência credenciado pelo Ministério da Agricultura, Pecuária e Abastecimento da Escola Superior de Agricultura "Luiz de Queiroz", onde se procedeu a leitura em contador eletrônico infravermelho(Bentley ${ }^{\circledR}$, Chaska, USA).

\section{Predição dos testes diagnósticos}

As predições dos testes diagnósticos foram mensuradas através da SE, ES, VPP, VPN e pela RP através das seguintes fórmulas (Tabela 2):

$$
\begin{aligned}
& \mathrm{SE}=\mathrm{P}(+\mid \mathrm{D}) \text { ou } \mathrm{C} /(\mathrm{C}+\mathrm{D}) \\
& \mathrm{ES}=\mathrm{P}(-\mid \mathrm{S}) \text { ou } \mathrm{B} /(\mathrm{A}+\mathrm{B}) \\
& \mathrm{VPP}=\mathrm{P}(\mathrm{D} \mid+) \text { ou } \mathrm{C} /(\mathrm{A}+\mathrm{C}) \\
& \mathrm{VPN}=\mathrm{P}(\mathrm{S} \mid-) \text { ou } \mathrm{B} /(\mathrm{B}+\mathrm{D}) \\
& \mathrm{RP}=\mathrm{SE} /(1-\mathrm{E} S) \\
& \text { Onde: } \mathrm{P}=\text { Probabilidade } \\
& \quad \mid=\text { Dado que } \\
& \quad \mathrm{D}=\text { Animal doente } \\
& \mathrm{S}=\text { Animal sadio } \\
& \quad+=\text { Animal positivo ao teste } \\
& \quad-\text { Animal negativo ao teste } \\
& \mathrm{A}=\text { Animal sadio, positivo no teste; } \\
& \mathrm{B}=\text { Animal sadio, negativo no teste; }
\end{aligned}
$$

$\mathrm{C}=$ Animal doente, positivo no teste;

$\mathrm{D}=$ Animal doente, negativo no teste.

A seleção dos valores de corte para os distintos testes foi estabelecida pelas distintas médias encontradas na literatura (VANLANDINGHAM et al., 1941; Sabbag et al., 1981; McDougall et al., 2001; Mulkalwar et al., 2001; Bianchiet al., 2004;Albenzio et al., 2005).

Tabela 2 - Resultados possíveis de um teste.

\begin{tabular}{lccc}
\hline Animal & Positivo & Negativo & Total \\
\hline Sadio & A & B & A + B \\
Doente & C & D & C + D \\
\hline Total & A + C & B + D & A + B + C + D
\end{tabular}

Fonte: CORTES (1993).

\section{Análise estatística}

Os dados foram analisados utilizando-se o programa estatístico MINITAB 15 Statistical Software ${ }^{\circledR}$ (MINITAB Inc., USA). A CCS foi transformada em escala logarítmica, já que a distribuição não foi normal. O efeito da presença bacteriana nas mamites clínica e subclínica sob exame físico da glândula mamária, CCS, CMT, pH, conteúdo de lactose e cloreto, eíndice cloreto-lactose foi avaliado utilizando One-Way Analysis of Variance (ANOVA) para a comparação das médias, seguido pelo teste de Tukey para comparações múltiplas. As correlações entreas diferentes variáveis quantitativas ( $\mathrm{CMT}, \mathrm{pH}$, conteúdo de cloreto e lactose, e índice cloreto-lactose) com a CCS foram determinadas pela correlação linear de Pearson (r). O valor de $\mathrm{p}<0,05$ foi considerado significante.

\section{RESULTADOS}

Na prova bacteriológica foram observadas 296 amostras (75,9\%) negativas e $94(24,1 \%)$ positivas. Destas, em $94,7 \%$ foram isoladas bactérias Staphylococcus spp., e em 5,3\% Streptococcus spp. Foram encontradas 290,92, 5 e 3 metades mamárias nos grupos G1, G2, G3 e G4, respectivamente. No exame físico, as médias ( \pm desvio-padrão) dos escores encontrados foram $1,55( \pm 1,14), 1,73( \pm 1,16), 2,40$ $( \pm 1,53)$ e 1,33 $( \pm 0,89)$ para os grupos G1, G2, G3 e G4, respectivamente $(p>0,23)$. Os valores (média \pm desvio-padrão) da CCS (log), CMT, pH, conteúdo de cloreto e lactose, e índice cloreto-lactose nos diferen- 
tes grupos estão apresentados na Tabela 3. Do mesmo modo, os valores de SE, ES, VPP, VPN e RP nos distintos grupos estão demonstrados na Tabela 4. As médias ( \pm desvio-padrão) da CCS (log), $\mathrm{CMT}, \mathrm{pH}$, conteúdo de cloreto e lactose, e índice cloreto-lactose foram 5,39 $( \pm 0,62)$ e $6,16( \pm 0,56)(p$ $>0,0001)$ para a CCS, $0,33( \pm 0,66)$ e $1,36( \pm 0,91)(\mathrm{p}$ $>0,0001)$ para o CMT, 6,80 $( \pm 0,24)$ e $6,95( \pm 0,27)$ (p $>0,0004)$ para $\mathrm{pH}, 113,64( \pm 46,45)$ e $138,94( \pm$ $51,65) \mathrm{mg} / \mathrm{dL}(\mathrm{p}>0,0001)$ para oconteúdo cloreto, $4,73( \pm 0,98)$ e $4,36( \pm 1,09) \mathrm{g} / \mathrm{dL}(\mathrm{p}>0,003)$ para o conteúdo a lactose, e 3,04 $( \pm 4,44)$ e 4,49 ( $\pm 6,78)$ (p
$>0,019)$ para o índice cloreto para as amostras negativas e positivas ao exame bacteriológico, respectivamente.

A correlação entre CMT, pH, o conteúdo de cloreto e lactose e o índice cloreto lactose com a CCS foram $\mathrm{r}=0,754(\mathrm{p}<0,0001), \mathrm{r}=0,416(\mathrm{p}<$ $0,0001), r=0,398(\mathrm{p}<0,0001), \mathrm{r}=0,504(\mathrm{p}<$ $0,0001)$ e $r=0,361(p<0,0001)$. As regressões lineares entre a CCS em escala logarítmica e as diferentes variáveis, assim como a equação da reta e o coeficiente de correlação, estão apresentadas nas Figuras de 1 a 5.

Tabela 3 - Contagem de Células Somáticas (CCS), California Mastitis Test, pH, conteúdo de cloreto e lactose, e índice cloreto-lactose nos distintos grupos.

\begin{tabular}{lcccc}
\hline Parâmetro/Grupo & $\mathrm{G} 1$ & $\mathrm{G} 2$ & $\mathrm{G} 3$ & $\mathrm{G} 4$ \\
\hline $\mathrm{CCS}(\log )$ & $5,36( \pm 0,60) \mathrm{b}$ & $6,16( \pm 0,57) \mathrm{a}$ & $6,57( \pm 0,46) \mathrm{a}$ & $6,37( \pm 0,32) \mathrm{a}$ \\
$\mathrm{CMT}$ & $0,3( \pm 0,60) \mathrm{b}$ & $1,34( \pm 0,91) \mathrm{a}$ & $1,80( \pm 1,10) \mathrm{a}$ & $2,00( \pm 1,00) \mathrm{a}$ \\
$\mathrm{pH}$ & $6,78( \pm 0,21) \mathrm{c}$ & $6,92( \pm 0,35) \mathrm{b}$ & $7,41( \pm 0,36) \mathrm{a}$ & $7,71( \pm 0,17) \mathrm{abc}$ \\
Cloreto $(\mathrm{mg} / \mathrm{dL})$ & $111,95( \pm 43,31) \mathrm{a}$ & $136,11( \pm 48,49) \mathrm{c}$ & $211( \pm 106,87) \mathrm{b}$ & $224,83( \pm 82,29) \mathrm{cb}$ \\
Lactose (mg/dL) & $4,79( \pm 0,88) \mathrm{a}$ & $4,41( \pm 1,02) \mathrm{b}$ & $1,49( \pm 1,14) \mathrm{c}$ & $1,88( \pm 1,76) \mathrm{c}$ \\
Índice Cloreto-Lactose & $2,748( \pm 3,569) \mathrm{c}$ & $3,935( \pm 4,643) \mathrm{b}$ & $19,474( \pm 13,226) \mathrm{a}$ & $28,315( \pm 31,677) \mathrm{a}$ \\
\hline
\end{tabular}

Letras diferentes indicam $p<0,01$

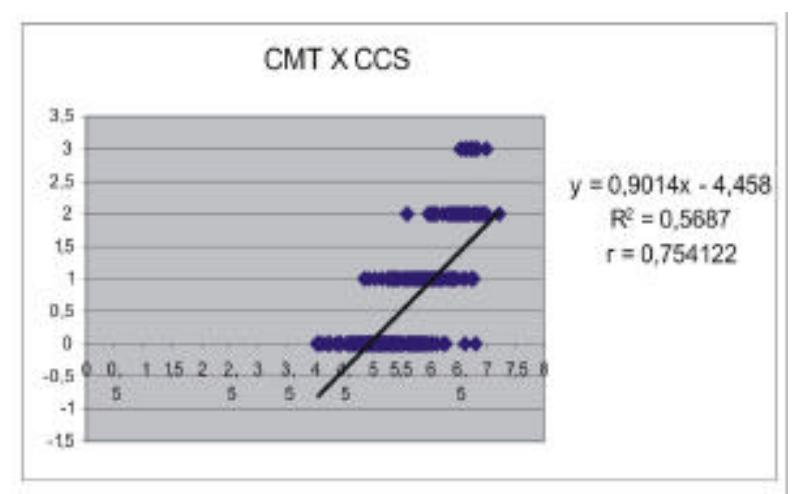

Fig. 1 - Regressão linear entre Contagem de Células Somáticas (CCS) e o California Mastitis Test (CMT).

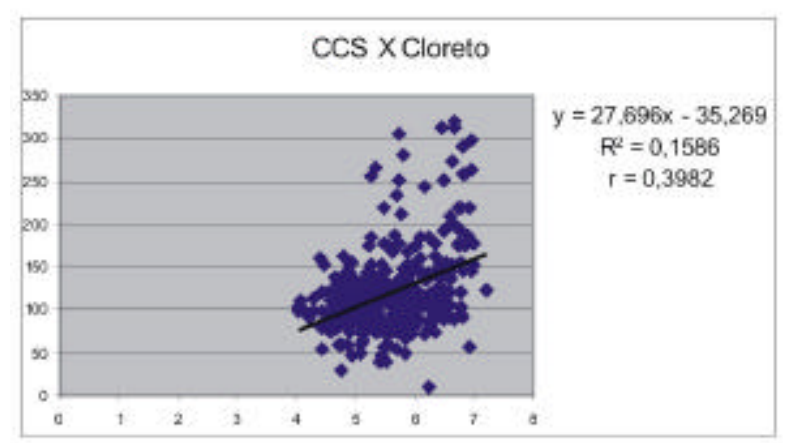

Fig. 3 - Regressão linear entre Contagem de Células Somáticas (CCS) e o conteúdo de cloreto.

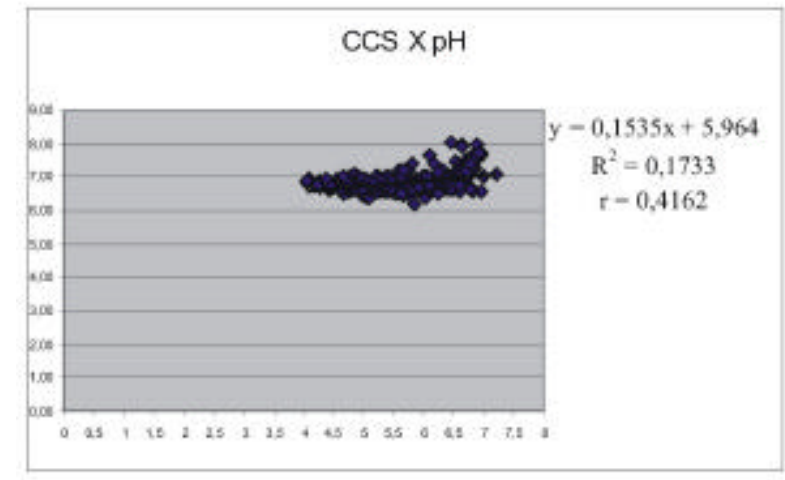

Fig. 2 - Regressão linear entre Contagem de Células Somáticas (CCS) e $\mathrm{pH}$.

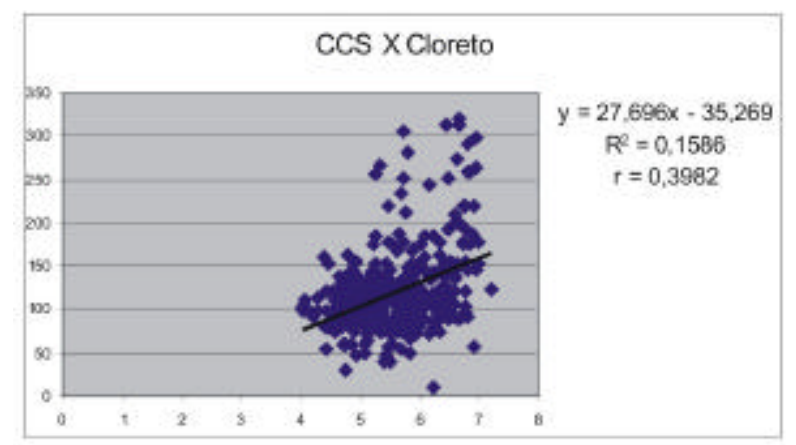

Fig. 4 - Regressão linear entre Contagem de Células Somáticas (CCS) e o conteúdo de lactose. 
Tabela 4 - Valores preditivos dos testes diagnósticos.

\begin{tabular}{ll} 
Variáveis & $\begin{array}{l}\text { Valores } \\
\text { de corte }\end{array}$ \\
& $5,477^{1}$ \\
& $5,699^{1}$ \\
& $6,000^{1}$ \\
& $0(\text { zero })^{1}$ \\
& $1(\text { um })^{1}$ \\
CMT & $2(\text { dois })^{1}$ \\
\hline pH & $6,71^{2}$ \\
& $6,85^{2}$ \\
\hline Cloreto & $182,12^{3}$ \\
\hline Lactose & $4,51^{4}$ \\
& $4,65^{4}$ \\
\hline Índice Cloreto-Lactose & $2,614^{6}$ \\
& $3,38^{5}$ \\
& $3,665^{6}$ \\
& $3,93^{5}$
\end{tabular}

Fig. 5 - Regressão linear entre Contagem de Células Somáticas (CCS) e Índice Cloreto-Lactose.

\section{DISCUSSÃO}

Os ovinos apresentam uma importância econômica em vários países e o seu número tem aumentado (Burriel, 1997). É relatada uma carência de estudos que abordam o diagnóstico da mamite ovina, especialmente daquelas raças que não são altamente especializadas para a produção deleite, como no caso a raça Santa Inês, raça com expressivo crescimento populacional no Brasil. Desta forma, meios diagnósticos de fácil execução e confiáveis para a detecção do processo inflamatório da glândula mamária são imprescindíveis para o diagnóstico desta enfermidade, principalmente ao considerar o tempo e os custos relacionados com a cultura bacteriológica. Tais medidas podem refletir em um aumento no desempenho de cordeiros, diminuição da mortalidade de cordeiros e redução do descarte e da mortalidade de matrizes.

No presente estudo utilizou-se o exame bacteriológico como padrão ouro, sendo que o isolamento bacteriano foi associado com aumento na CCS, no $\mathrm{CMT}$, no $\mathrm{pH}$, no teor de cloretos e no índice cloretolactose, edecréscimo noteor delactose. Noentanto, não seobservaram diferenças ao examefísico, demonstrando desta forma a importância da associação de meios diagnósticos indiretos na detecção desta enfermidade. O mesmo foi observado em relação às amostras negativas em relação aos demais grupos, sendo geralmente observadas mudanças mais marcantes nas metades mamárias positivas à prova defundoescuro, mesmo ao considerar o pequeno número de amostras positivas a tal exame, o que muitas vezes pode refletir a não significância encontrada.

As mamites estreptococcicas representaram 5,6\% neste estudo, o que está de acordo com LeITNER et al. (2001) e Bergonier et al. (2003). Grande parte das amostras positivas à prova bacteriológica foi Staphylococcus spp., sendo que esta corresponde à principal causa dos quadros considerados subclínicos em ovelhas (BERGONIER et al., 2003; CONTRERAs et al., 2007). Geralmente, caracteriza-se como mamite subclínica a manifestação sem sinais 
físicos da mama, mas com redução da produção de leite e aumento da celularidade deste. Destarte esses serem sinais, a manifestação não pode ser considerada assintomática e, por vezes, é inadequado o termo subclínico. O diagnóstico da mamite subclínica em ovelhas da raça Santa Inês fica ainda mais limitado, já que essas fêmeas não são sistematicamente ordenhadas, o que justificaria a indicação da realização periódica de provas indiretas para o seu diagnóstico.

Não foram observadas diferenças ao exame físico da mama, o que sugere a necessidade de uma abordagem mais ampla deste exame com a avaliação de outras variáveis como pendulosidade mamária, presença de soluções de continuidade no teto e presença de nódulos (Blagitz, 2007).

A contagem de células somáticas é um marcador inflamatório da glândula mamária, já que a maior parte das subpopulações celulares se origina do sangue pela quimiotaxia e diapedese em resposta a uma agressão local (BERGONIER; BERTHELOT , 2003; LAFI, 2006). Este teste apresentou-se como um bom preditor para a determinação da presença bacteriana, principalmente ao utilizar o valor logarítmico de corte de 5,699. Na mamite, como os custos com tratamento ou descarte devem ser considerados, e o objetivo concentra-se na redução da prevalência da infecção sem probabilidade de eliminação da doença, a especificidade apresenta prioridade em relação à sensibilidade. Assim, o objetivo de selecionar valores de corte para esta enfermidade é maximizar a especificidade mantendo a sensibilidade em valores razoáveis desde que a maioria dos casos seja identificada (CLEMENTs et al., 2003; LAFI, 2006). Ovalor de corte sugerido apresentase de acordo com grande parte dos valores sugeridos na literatura $(5,398$ a 6,230) (GonZALEZ-RodRIGUES; Carmenes, 1994; Danków et al. apud Menzies; RAMANOON, 2001). A alta SE e ES também foram descritas por McDougALL et al. (2001) e LAFI (2006).

Oescore de CMT foi positivamente correlacionado coma CCSe presença bacteriana (CONTRERAs et al.,2007; PYöRALÄ, 2003). Assim, a maior correlação com a CCS foi encontrada com este teste. O escore 1 do CMT pode ser recomendado para a discriminação entre os animais, considerando que este escore apresentou a boa especificidade sem comprometer demasiadamente a sensibilidade, além de um maior valor da razão de probabilidades, porém a literatura é controversa em relação aos valores de corte a serem utilizados (GonZAlez-Rodrigues;CARMENES, 1994). Deve-sesalientar que variações entre os estudos são reportadas, sendo estas principalmente devido a diferenças metodológicas como a definição do animal infectado, valores de cortes empregados (1 a 3) (McDougall etal., 2001).

Segundo Schalm etal. (1971), a leve acidez do leite está relacionada aos grupos ácidos livres da caseína, citrato e fosfato, além da presença de $\mathrm{CO}_{2}$ dissolvido. Estes mesmos autores relatam que o aumento do $\mathrm{pH}$ durante a mamite está associado com o aumento da permeabilidade da glândula mamária aos componentes sangüíneos, o que faz com que ocorra a migração de componentes alcalinos do sangue, principalmente o íon bicarbonato. Contudo, os valores preditivos encontrados foram apenas razoáveis ao confrontar com os demais testes. Deve-se considerar que os valores médios encontrados de 6,796 para os animais sadios e 6,947 para os infectados encontram-se acima dos relatados pela literatura, 6,51 a 6,71 para os animais com baixa CCSe 6,63 a 6,93 para os com alta CCS (BiAnchi et al., 2004; Albenzio et al., 2005).

Os principais íons presentes no leite são $\mathrm{Na}^{+}, \mathrm{K}^{+} \mathrm{e}$ $\mathrm{Cl}^{-}$. Os íons cloreto e os íons sódio estão presentes na circulação sangüínea e, durante a mamite, atravessam os capilares sangüíneos, direcionando-se ao lúmen dos alvéolos da glândula mamária. Tal processo ocorre devido ao aumento da permeabilidade vascular e à destruição das junções celulares e do sistema. de bombeamento iônico causados pelo processo inflamatório (ZAFALON et al., 2005), ao considerar que a concentração de cloro é maior no sangue e no fluido extracelular que no leite (KITCHEN, 1981). Este teste foi o melhor preditor da presença bacteriana, juntamente com a CCS e o CMT, apresentando alta SE, ES, VPP, VPN e RP. Observou-se também uma correlação positiva com a CCS como já descrito por Peris et al. (1991). No entanto, vários autores ao avaliarem a condutividade elétrica do leite, que é determinada pela concentração iônica, relataram uma baixa predição deste teste (RUEGG; REINEMAN, 2002), podendo a predição dos testes da condutividade elétrica e do teor de cloreto ser influenciada pelo patógeno envolvido (ZAFALON et al., 2005), além do conhecido efeito do $\mathrm{pH}$ e do teor de gordura na avaliação destes parâmetros (PYörAlä, 2003).

Um decréscimo do conteúdo de lactose é descrito, sendo este resultante da sua passagem para o fluido extracelular e para o sangue como resultado da destruição parcial do tecido secretor, que constitui uma barreira natural à lactose e redução da sua biossíntese causada pela destruição de grande número de células epiteliais decorrente do processo inflamatório (PYÖRAlä, 2003). Os valores encontrados estão dentro do relatado na literatura para os animais sadios e para os infectados (ALBENZIo et al., 2004). A predição deste teste foi relativamente baixa, o que concorda com BERNING; SHOOK (1992), entretanto foi observada uma correlação negativa com a CCS. A utilização deste parâmetro pode ser comprometida, já que essas mudanças são geralmente sutis (BERNING;SHOOK,1992).

Como apresentado anteriormente, nos casos de mamite, o teor de cloretos aumenta enquanto a con- 
centração de lactose diminui, portanto o cálculo do índice cloreto-lactose é tido também como meio do diagnóstico indireto (VANLANDINGHAM et al.,1941). Até onde se pode investigar, não foram encontrados trabalhos na literatura que determinaram a avaliação deste parâmetro para ovinos. Porém, este não se apresentou como um bom preditor, ficando aquém dos demais, provavelmente devido a menor predição da lactose encontrada ou aos valores de corte de bovinos utilizados que não representariam uma realidade para esta espécie.

A variação entre os estudos na determinação dos valores dos testes indiretos para o diagnóstico da mamite ovina pode ser devida a diferenças metodológicas como a definição da infecção intramamária, ovalor decorteutilizadoea prevalência da enfermidade dentro da população estudada (McDougall et al., 2001).

Todavia, estes parâmetros podem ser influenciados por fatores como idade, estágio lactacional, produção, estação do ano, fração láctea coletada, infecções virais como Maedi-Visna e variações entre animais (BERGONIER et al., 2003). Inclui-se, também, a patogenicidade do agente etiológico envolvido a qual determina a intensidade da resposta inflamatória podendo refletir na avaliação dos testes analisados (GonZALoet al., 2002; ZAFALON et al., 2005) como, por exemplo, a diferença observada entre cepas de Staphylococcus coagulase negativa resistentes ou sensíveis a novobiocina (GonzAlo et al., 2002). Ainda, grande parte da predição dos testes diagnósticos é baseada no exame bacteriológico como padrão ouro, no entanto a mamite nem sempre requer a presença bacteriana (PYÖRALÄ, 2003).

\section{CONCLUSÃO}

A CCS, o CMT e o conteúdo de cloretos apresentaram-se com ferramentas confiáveis para o diagnóstico da mamite ovina, não podendo o mesmo ser aplicado para os demais testes.

\section{AGRADECIMENTOS}

À FAPESP pelo apoio financeiro concedido e ao CNPq pela concessão da bolsa.

\section{REFERÊNCIAS}

ALBENZIO, M.; CAROPRESE, M.; SANTILLO, A.; MARINO, R.; MUSCIO A.; SEVI A. Proteolytic patterns and plasmin activity in ewe's affected by somatic cell count and stage of lactation. Journal of Dairy Research, v.72, p.86-92, 2005.
ALBENZIO, M.; CAROPRESE, M.; SANTILLO, A.; MARINO, R.; CENTODUCATI, P.; SEV I A. Effects on somatic cell count and stage of lactation on the plasmin activity and cheese-making properties of ewe milk. Journal of Dairy Science, v.87, p.533-542, 2004.

AULDIST, M.J.; COATS, S.; ROGERS, G.L.; MCDOWELL, G.H. Changes in the composition of milk from heathy and mastitic dairy cows during the lactation cycle. Australian Journal of Experimental Agriculture, v.35, p.427-436, 1995.

BAUMGARTNER, W. Klinische Propädeutik der inneren krankheiten und hautkrankheiten der haus und heimtiere. 6.ed. Berlim-Wien: Parey, 2005. 382p.

BERGONIER, D.; BERTHELOT, $X$. New advances in Epizootiology and control of ewe mastitis. Livestock Production Science, v.79, p.1-16, 2003.

BERGONIER, D.; CRÉMOUX, R.; RUPP, R.; LAGRIFFOUL, G.; BERTHELOT, X. Mastitis in Small Ruminants. Veterinary Research, v.34, p.689-716, 2003.

BERNING, L.M.; SHOOK, G.E. Prediction of mastitis using somatic cell count, N-acetyl- $\beta$-D-glucosamide and lactose. Journal of Dairy Science, v.75, p.1840-1848, 1992.

BIANCHI, L.; BOLLA, A.; BUDELLI, E.; CAROLI, A.; CASOLI, C.; PAUSELLI, M.; DURANTI, E. Effect of udder health status and lactation phase on characteristics of Sardinian ewe milk. Journal of Dairy Science, v.87, p.2401-2408, 2004.

BLAGITZ, M.G. Avaliação da relação do exame físico da glândula mamária de ovelhas da raça Santa Inês com o perfil citológico e bacteriológico do leite. 195p. Dissertação (Mestrado) - Departamento de Clínica Médica. Faculdade de Medicina Veterinária e Zootecnia, Universidade de São Paulo, São Paulo, 2007.

BURRIEL, A.R. Dynamics of intramammary infection in the sheep caused by coagulase-negative staphylococci and its influence on udder tissue and milk composition. Veterinary Record, v.140, p.419-423, 1997.

CLEMENTS, A.C.A.; TAYLOR, D.J.; FITZPATRICK, J. Evaluation of diagnostic procedures for subclinical mastitis in meat-producing sheep. Journal of Dairy Research, v.70, p.139-148, 2003.

CONTRERAS, A.; SIERRA, D.; SÁNCHEZ, A.; CORRALES, J.; MARCO, J.; PAAPE, M.; GONZALO, C. Mastitis in small ruminants. Small Ruminant Research, v.68, p.145-153, 2007.

CORTES, J.A. Epidemiologia: conceitos e fundamentos. São Paulo: Varella, 1993.

FTHENAKIS, G.C.; JONES, J.E.T. The effect of experimental induced clinical mastitis on milk yield of ewes and on the growth of lambs. British Veterinary Journal, v.146, p.43, 1990. 
GONZALEZ-RODRIGUES, M.C.; CARMENES, P. Evaluation of the California Mastitis Test as a discriminant method to detect subclinical mastitis in ewes. Journal of Dairy Science, v.77, p.1537-1542, 1994.

GONZALO, C.; ARIZNABARRETA, A.; CARRIEDO, J.A. Mammary pathogens and their relationship to somatic cell count and milk yield losses in dairy ewes. Journal of Dairy Science, v.85, p.1460-1467, 2002.

GREEN, T.J. Use of somatic cell couns for detection of subclinical mastitis in ewes. Veterinary Record, v.114, p.43, 1984 .

GRUNERT, E. Sistema genital feminino. In: DIRKSEN, G.; GRÜNDER, H.D.; STÖBER, M. (Ed.) Exame clínico dos bovinos. 3.ed. Rio de Janeiro: Guanabara Koogan, 1993. p.269-314.

KITCHEN, B. Review of the progress of dairy science: Bovine Mastitis: Milk compositional changes and related diagnostic tests. Journal of Dairy Research, v.48, p.167-188, 1981.

KRIEG, N.R.; HOLT, J.C. Bergey's manual of systematic bacteriology. 9.ed. Baltimore: Willians \& Wilkins, 1994.

LAFI, S.Q. Use of cell counts and California Mastitis Test results from udder halves milk samples to detect subclinical intramammary infection in Awassi sheep. Small Ruminant Research, v.62, p.8386, 2006.

LARSGARD, A.G.; VAABENOE, A.Genetic and environment causes of variation in mastitis in sheep. Small Ruminant Research, v.12, p.339-347, 1993.

LEITNER, G.; CHAFFER, M.; ZAMIR, S.; MOR, T.; GLICKMAN, A. Udder disease etiology, milk somatic cell counts and NAGase activity in Israeli Assaf sheep throughout lactation. Small Ruminant Research, v. 39, p.107-112, 2001.

LENNETE, E.M.; BALOWS, A.; HAUSLER, W.J.; TRUANT, J.P. Manual of clinical microbiology. 4.ed. Washington: American Society of Microbiology, 1985.

Markovec, J.A.; Ruegg, P.L.. Characteristics of milk samples submitted for culture in Wiscosin from 19942000. International Journal of Dairy Science, v. 85, p.85, 2002. Suplemento 1.
MCDOUGALL, S.; MURDOUGH, P.; PANKEY, W.; DENANEY, C.; BARLOW, J.; SCRUTON, D.

Relationship among somatic cell count, California mastits test, impedance and bacteriological status of milk in goats and sheep in early lactation. Small Ruminant Research, v.40, p.245-254, 2001.

MENZIES, P.R.; RAMANOON, S.Z. Mastitis of sheep and goats. Veterinary Clinics of North America: Food Practice, n.2, p.333-355, 2001.

MULKALWAR, D.B.; PARKHI, C.P.; MANGLE, N.S.; KALORE, D.R.; KOTHEKAR, M.D. Effect of udder heath on total whey protein, immunoglobulin, and chloride level in sheep milk. Indian Vet. Journal, v. 78, p. 544-546, 2001.

PERIS, C.; MOLINA, P.; FERNANDEZ, N.; RODRIGUES, M.; TORRES, A. Variation in somatic Cell Count, California Mastitis Test, and Electrical Conductivity Among Various Fractions of Ewe's Milk. Journal of Dairy Science, v.74, p.1553-1560, 1991.

PYÖRALÄ, S. Indicators of inflammation in the diagnosis of mastitis. Veterinary Research, v.34, p.565-578, 2003.

RUEGG, P.L.; REINEMANN, D.J. Milk quality and mastitis test. Bovine Practice, v.36, p.41-54, 2002.

SABBAG, N.G.; ESPONDA, J.C.; FREYRE, M.R. Estudio de algunos parametros fisico-quimicos de interes tecnologico em leches normales y mastiticas. Revista del Instituto de Tecnologia de Alimentos, v.3, n.1, p.99- 106, 1981.

SCHALM, O.W; CARROL, E.J.; JAIN, N.C. Bovine mastitis. Philadelphia: Lea \& Febiger, 1971. 360p.

VANLANDINGHAM, A.H.; CHAS, E.; WEAKLEY, J.R.; MOORE, E.N.; HENDERSON, H.O. Mastitis. I.

Relationship of the development of mastitis to changes in the chlorine, lactose and casein number of milk. Journal Dairy Science, v.24, n.1, p.383-398, 1941.

ZAFALON L.F.; NADER FILHO A.; OLIVEIRA J.V.; RESENDE F.D. Comportamento da condutividade elétrica e do conteúdo de cloretos como métodos auxiliares de diagnóstico da mamite subclínica bovina. Pesquisa Veterinária Brasileira, v.25, n.3, p.150-163, 2005.

Recebido em 24/8/07

Aceito em 29/8/08 